\title{
Postmeal Glucose Compared to Oral Glucose Tolerance in Non-Diabetic Patients with Acute Myocardial Infarction
}

\author{
O.T. Arola ${ }^{*}$, , P.I. Nevalainen ${ }^{2}$, M. Kotila ${ }^{3}$, H. Huhtala ${ }^{4}$ and J. Alanko ${ }^{5}$ \\ ${ }^{1}$ The Heart Hospital, Tampere University Hospital, Tampere, Finland \\ ${ }^{2}$ Department of Internal Medicine, Tampere University Hospital, Tampere, Finland, and School of Medicine, University \\ of Tampere, Tampere, Finland \\ ${ }^{3}$ Seinäjoki Central Hospital, Seinäjoki, Finland \\ ${ }^{4}$ School of Health Sciences, University of Tampere, Tampere, Finland \\ ${ }^{5}$ Valkeakoski Regional Hospital, Valkeakoski, Finland
}

\begin{abstract}
Background: Abnormal glucose tolerance (AGT) in non-diabetic patients with acute myocardial infarction is associated with decreased survival compared to those with normal glucose tolerance (NGT). The aim of this study was to test if two-hour postprandial glucose (PPG2h) after a mixed meal correlates with the two-hour oral glucose tolerance test (OGTT2h).

Methods: We prospectively enrolled 189 non-diabetic patients with acute myocardial infarction.

Results: According to the oral glucose tolerance test (OGTT), 37.0\% had NGT, $4.8 \%$ had impaired fasting glucose, $37.6 \%$ had impaired glucose tolerance (IGT) and $20.6 \%$ had diabetes. PPG $2 \mathrm{~h}$ after each meal correlated with OGTT2h $\left(\mathrm{R}^{2}=\right.$ $0.13-0.26, \mathrm{P}<0.001)$. In diabetic patients, PPG2h levels after each meal were higher $(\mathrm{p}<0.01$ for all $)$ than in the IGT and NGT group. In the NGT and IGT group, PPG2h was higher after lunch and dinner than after breakfast ( $p<0.01$ ), but this was not the case in the diabetic patients. In detecting diabetes compared to OGTT2h, PPG2h equal to or above $5.6 \mathrm{mmol} / 1$ after breakfast, $6.5 \mathrm{mmol} / 1$ after lunch and $7.0 \mathrm{mmol} / \mathrm{l}$ after dinner had a sensitivity of at least $76 \%$ and specificity of at least $42 \%$. Glucose values below the cut-off values suggest that OGTT need not be evaluated.

Conclusion: PPG2h is a quick, practical, simple and easy measurement in clinical practice. PPG2h correlates with OGTT but the value is lower, so PPG2h cannot be used to evaluate postprandial glycemia with the current OGTT glycemic thresholds. We therefore suggest the use of new cut-off values for PPG2h after a random meal to select patients in whom OGTT is not needed to evaluate diabetic status.
\end{abstract}

Keywords: Abnormal glucose tolerance, acute myocardial infarction, impaired glucose tolerance, newly diagnosed diabetes, oral glucose tolerance test, postprandial glucose, stress-induced hyperglycemia.

\section{INTRODUCTION}

Physiological variation of plasma glucose is tightly controlled after either prolonged fasting or a meal; it is generally between 4 and $7 \mathrm{mmol} / \mathrm{l}$ in humans. Glycosylated hemoglobin $\mathrm{A}_{1 \mathrm{c}}\left(\mathrm{HbA}_{1 \mathrm{c}}\right)$ provides a method for approximating plasma glucose concentration during the previous 2 to 3 months [1,2]. $\mathrm{HbA}_{1 \mathrm{c}}$ measurements are the mainstay of monitoring long-term glycemic control in patients with diabetes mellitus. Fasting plasma glucose (FPG) and two-hour oral glucose tolerance test (OGTT2h) levels correlate significantly with $\mathrm{HbA}_{1 \mathrm{c}}$ within its reference range. However, OGTT2h is a more sensitive indicator of abnormal glucose tolerance (AGT) than either FPG or $\mathrm{HbA}_{1 \mathrm{c}}$ [2]. The development of type 2 diabetes progresses from normal glucose homeostasis to postprandial hyperglycemia and only then to fasting hyperglycemia [3].

Address correspondence to this author at the Heart Hospital, Tampere University Hospital, P.O. Box 2000, FI-33521 Tampere, Finland;

Tel: +358 3 3116 611; Fax: +358 3 3116 4157; E-mail: olli.arola@sydansairaala.fi
Insulin secretion was first demonstrated to be biphasic over 40 years ago [4]. After a hyperglycemic stimulus, insulin concentration in plasma rises rapidly within minutes, corresponding to first-phase insulin secretion, and decreases after 10-15 minutes. The gradual rise in plasma insulin concentrations that represent the second-phase secretion can be measured in the 2-3-hour period after glucose intake [4]. Type 2 diabetes is a polygenic disorder in which environmental or acquired factors modulate the risk and phenotype of the disease. Both hereditary and modulating factors can affect beta-cell function and insulin sensitivity [4]. First-degree relatives of type 2 diabetes have reductions in first- and second-phase insulin release while having no change in insulin sensitivity [4,5]. Thus, impaired first-phase insulin secretion and the resulting postprandial hyperglycemia is a primary defect for impaired glucose tolerance (IGT) and type 2 diabetes. Several mechanisms might explain perturbations of the biphasic insulin secretion in a pathological situation [6]. Reduced first-phase insulin secretion is responsible for the impaired inhibition of hepatic 
glucose output postprandially in IGT and type 2 diabetes. Together with diminished peripheral glucose uptake, these perturbations contribute to postprandial hyperglycemia [5].

The worldwide epidemic of type 2 diabetes and its complications is a growing problem. According to large cohort studies, patients with diabetes or pre-diabetic conditions are at higher risk for cardiovascular events than those with normal glucose tolerance (NGT) [1,7]. Diabetic patients and also newly-detected diabetes or IGT patients are also at a high risk for death and cardiovascular events after acute myocardial infarction [8-10]. Furthermore, there is evidence that postchallenge glucose is associated with adverse cardiovascular outcomes and death in both the diabetic and non-diabetic populations [1,7,11-13]. Thus, most epidemiological data implicate postprandial hyperglycemia in the development of cardiovascular diseases, while the link between fasting glycemia and diabetic complications is inconclusive [14]. Cavalot et al. [11] found that postprandial glucose (PPG) predicted cardiovascular events better than fasting plasma glucose (FPG) in patients with type 2 diabetes, especially in women. The European Society of Cardiology and the European Association for the Study of Diabetes recommend that an oral glucose tolerance test (OGTT) is indicated if $\mathrm{HbA}_{1 \mathrm{c}}$ and/or FPG are inconclusive in patients with cardiovascular disease [15].

FPG is more practical than OGTT for evaluating cardiovascular risk. However, AGT defined by OGTT is better for determining cardiovascular prognosis after myocardial infarction [8]. OGTT is a non-physiological test of glucose absorption that classifies patients by their metabolic characteristics. Normally, people eat two to four major mixed meals per day with a varying carbohydrate, protein and fat content. Thus, glycemic excursion after a meal is lower than after OGTT [16]. The everyday picture is thus better reflected by PPG2h than OGTT2h. A standard mixed meal may not always be applicable, and it is not known whether a random PPG2h can be used to estimate a standardized OGTT2h result.

In the Diabetes Intervention Study (DIS), PPG was an independent risk factor for death in patients with type 2 diabetes [13], while in the STOP-NIDDM Study [12], decreasing PPG with acarbose was associated with a lower incidence of cardiovascular events in patients with IGT. By contrast, the HEART2D Study [17] found no difference in future cardiovascular event rates after myocardial infarction between prandial strategy groups and basal strategy groups in diabetic patients, while the difference of PPG between the groups was negligible.

The aim of this study was to evaluate PPG2h compared to OGTT2h in patients with acute myocardial infarction without known diabetes.

\section{MATERIALS AND METHODS}

\section{Subjects}

Patients with confirmed myocardial infarction $[18,19]$ and without known diabetes or receiving antihyperglycemic treatment were enrolled between September 2006 and July 2008 at Tampere University Hospital and Seinäjoki Central Hospital. The final cohort consisted of 189 out of 229 enrolled patients (Fig. 1). Patient demographics are given in (Fig. 1). All coronary interventions were performed at Tampere University Hospital.

Inclusion criteria were a verified acute myocardial infarction, an age between 18 and 90 years, plasma glucose < $11.1 \mathrm{mmol} / 1$ (divide by 0.05551 to get $\mathrm{mg} / \mathrm{dl}$ ) at admission, and an ability and allowance to eat regular food containing carbohydrates. Myocardial infarction was diagnosed in cases of two measurements of an elevated serum troponin $\mathrm{T}$ concentration $(>0.03 \mu \mathrm{g} / \mathrm{l})$ and either typical symptoms of myocardial ischemia (chest pain lasting $>15$ minutes, or pulmonary edema in the absence of cardiac valvular disease, or cardiogenic shock, or ventricular tachycardia or fibrillation) or electrocardiogram changes (ST changes, new left bundle branch block, or new pathologic Q waves) $[18,19]$. Patients with previously diagnosed diabetes or receiving antihyperglycemic treatment, and/or renal insufficiency treated with dialysis were excluded. Demographic and clinical information was collected during the hospital stays.

Hypertension was recorded if treated prior to enrollment. Smoking history was recorded if the patient smoked or had smoked regularly. Previous myocardial infarction was recorded if previously treated or diagnosed. Atherosclerotic disease was recorded if treated surgically or percutaneously, or if a patient had typical symptoms (for example claudication). Family history was recorded if there was cardiovascular disease in the family at a young age (under 50). Stroke was recorded if previously diagnosed.

The glucometabolic state was classified based on the World Health Organization criteria [16] for plasma glucose. NGT was recognized as FPG $<6.1 \mathrm{mmol} / 1$ and OGTT2h glucose $<7.8 \mathrm{mmol} / \mathrm{l}$, impaired fasting glucose as fasting glucose 6.1-6.9 $\mathrm{mmol} / 1$ and OGTT2h glucose $<7.8 \mathrm{mmol} / 1$, IGT as FPG $<7.0 \mathrm{mmol} / 1$ and OGTT2h glucose 7.8-11.0 $\mathrm{mmol} / \mathrm{l}$, and diabetes as FPG $\geq 7.0 \mathrm{mmol} / \mathrm{l}$ or OGTT2h glucose $\geq 11.1 \mathrm{mmol} / \mathrm{l}$. Patients were classified as having AGT when FPG was $\geq 6.1 \mathrm{mmol} / 1$ or OGTT2h $\geq 7.8 \mathrm{mmol} / 1$.

Waist circumference was defined as centimeters above risk limit (women $>88 \mathrm{~cm}(>35$ ") and men $>102 \mathrm{~cm}(>40 ")$ ).

All patients received standard cardiac care. Angiography was performed on all but 18 patients who had either contraindication for antithrombotic therapy or whose symptoms stabilized with conservative care. Fifteen out of 171 angiographed patients were not revascularized because of clinically negligible coronary stenoses.

\section{Biochemical Analyses}

Admission plasma glucose was measured with Lifescan One Touch $^{\circledR}$ Ultra $^{\circledR} 2$. $\mathrm{HbA}_{1 \mathrm{c}}$ was analyzed immunochemically (normal range 4.0-6.5\%, Tina Quant ${ }^{\circledR}$, Roche, Basel, Switzerland). Venous blood was drawn during OGTT (at 0 and $120 \mathrm{~min}$ ). PPG plasma glucose was measured 120 min after breakfast, lunch and dinner with an ARKRAY Glucocard X-meter GT-1910.

The patients' glucometabolic states were evaluated with OGTT not earlier than 24 hours after admission to hospital, and PPG2h was measured two hours after breakfast, lunch and dinner. OGTT ( $75 \mathrm{~g}$ glucose in $330 \mathrm{ml}$ water; Glukodyn ${ }^{\circledR}$ ) and PPG measurements were performed on the ward during 


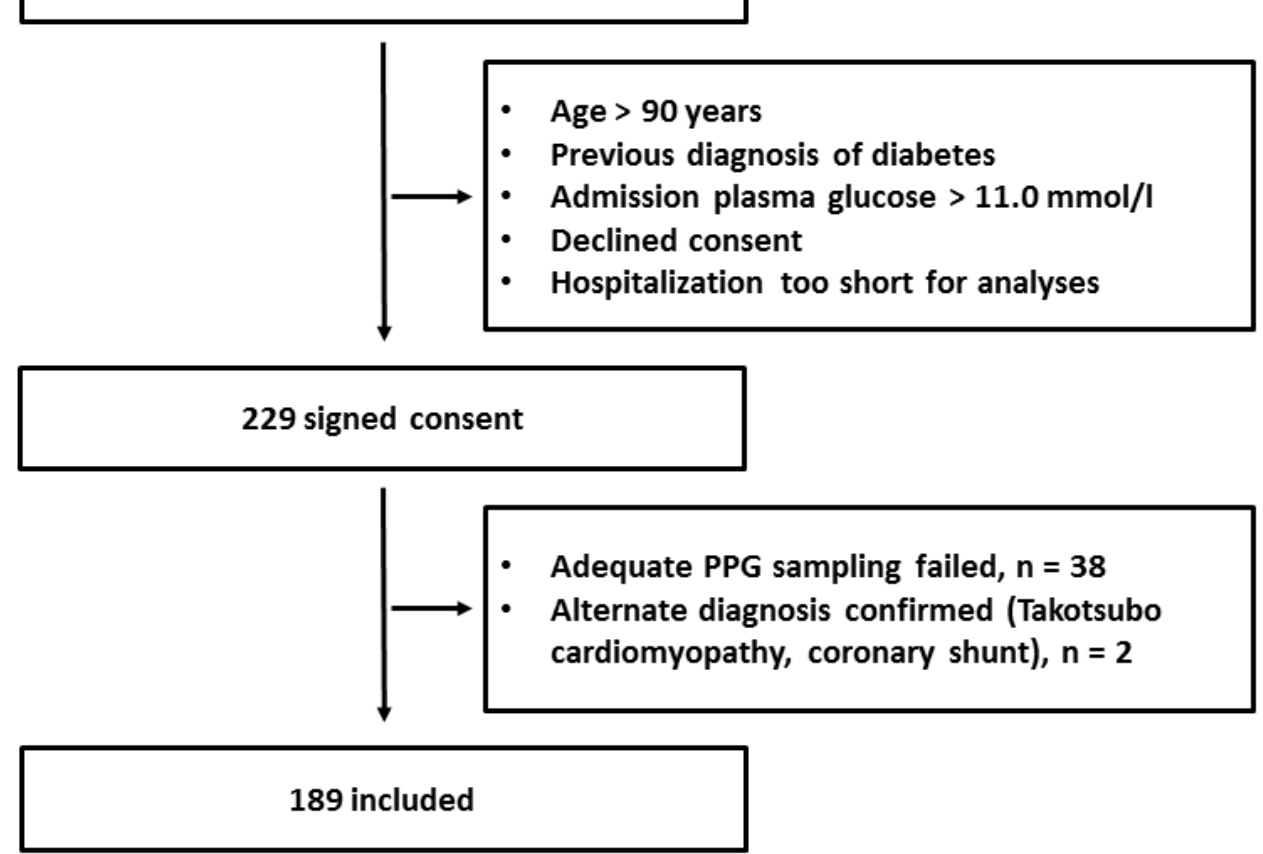

Fig. (1). Flowchart. $P P G=$ postprandial glucose.

stable conditions before discharge. Mean hospital diet content was calculated from the daily content of meals over seven consecutive days during the study (Table $\mathbf{3}$ ).

Plasma creatinine, total cholesterol and triglycerides were analyzed by a photometric enzymatic method and plasma high-density lipoprotein (HDL) cholesterol was analyzed by a direct enzymatic method (Integra ${ }^{\circledR}$, Roche, Basel, Switzerland). Low-density lipoprotein cholesterol was calculated by the Friedewald equation (Friedewald 1972). Troponin $\mathrm{T}$ was analyzed immunologically (Elecsys ${ }^{\circledR}$, Roche, Basel, Switzerland). The estimated glomerular filtration rate (GFR) was calculated by the Cockroft-Gault formula and the modification of diet in renal disease (MDRD) formula [20,21].

All blood sampling and OGTTs were performed by the internationally accredited laboratory of the adjacent university hospital (Laboratory and Pharmacy Public Utility of Pirkanmaa Hospital District, Tampere, Finland).

\section{Statistics}

The normality of the variables was assessed graphically. Continuous variables are presented as means (SD) or, when distribution was non-parametric, as means (Q1, Q3), and categorical variables as counts and proportions (\%). Patients whose glucometabolic state was not properly classified were excluded from the analysis. The normality of continuous values was tested with the D'Agostino-Pearson test. The correlation between variables was tested with Pearson's correlation coefficient, with the exception of troponin $\mathrm{T}$ and triglycerides, which were tested with Spearman's rho. Differences in baseline characteristics were compared using the Chi-squared test, a two-tailed Fisher's exact test, the independent samples t-test and the Mann-Whitney U-test (SPSS 11.5, Chicago, IL, USA). The receiver operating characteristics (ROC) curve approach was used to evaluate sensitivity and specificity of PPG $2 \mathrm{~h}$ in detecting diabetes at each meal compared to OGTT2h. We emphasized sensitivity over specificity because we consider PPG2h to screen patients for further evaluation by OGTT.

\section{Ethics}

The study protocol was approved by the Ethics Committee of Tampere University Hospital and conducted according to the Declaration of Helsinki. All patients gave their written, informed consent.

\section{RESULTS}

According to FPG, 134 (70.9\%) patients were healthy, 47 $(24.9 \%)$ had IFG, and $8(4.2 \%)$ were diabetic. According to standardized OGTT, $70(37.0 \%)$ patients had NGT, $9(4.8 \%)$ had isolated increased fasting glucose, 71 (37.6\%) had IGT, and $39(20.6 \%)$ had diabetes. Thus, 79\% (31/39) of newly diagnosed cases of diabetes would have been missed using fasting glucose only. The mean time from admission to hospital to PPG2h assessment was 5 (4) days (range 1-30 days) and the corresponding time to OGTT assessment was 6 (4) days (range 1-31 days). OGTT2h glucose did not decrease with increasing time from acute myocardial infarction $\left(\mathrm{r}_{\mathrm{s}}=0.006, \mathrm{p}=0.934\right)$.

The AGT group had lower HDL cholesterol, higher body mass indexes and triglycerides, more frequent hypertension and larger waists than patients with NGT (Tables 1 and 2).

The mean and range of carbohydrate content of breakfast, lunch and dinner was 48g (43-51), 58g (47-67) and 62g (49$83 \mathrm{~g}$ ) respectively in routine weekday hospital meals (Table 3). PPG2h levels after each meal in the NGT, IGT and diabetes groups are shown in (Fig. 2). In patients with newly diagnosed diabetes, PPG2h levels after each meal were 
higher than in the IGT $(\mathrm{p}<0.001$ for breakfast, $\mathrm{p}=0.014$ for lunch and $\mathrm{p}=0.007$ for dinner) and NGT groups ( $\mathrm{p}<0.001$ for breakfast, $\mathrm{p}=0.001$ for lunch and $\mathrm{p}<0.001$ for dinner). PPG2h did not differ between the NGT and IGT groups after any meal $(p=0.075$ for breakfast, $p=0.586$ for lunch and $p=0.056$ for dinner).

Table 1. Demographics of patients with normal (NGT) or abnormal glucose tolerance (AGT) in hospital. Values are given either as number (\%) or as mean (SD).

\begin{tabular}{|l|c|c|c|}
\hline & NGT & AGT & P \\
\hline \hline No. of patients & 70 & 119 & \\
\hline Sex, F/M & $26 / 44$ & $35 / 84$ & 0.272 \\
\hline Age, mean (SD), y & $66(12)$ & $65(12)$ & 0.656 \\
\hline BMI, mean (SD), kg/m² & $27(4)$ & $29(5)$ & 0.024 \\
\hline Waist $>88 / 102 \mathrm{~cm} \mathrm{( \% )})^{\mathrm{a}}$ & $39(56)$ & $82(69)$ & 0.089 \\
\hline Smoking (\%) & $33(47)$ & $68(57)$ & 0.213 \\
\hline Hypertension (\%) & $34(49)$ & $84(71)$ & 0.011 \\
\hline Family history (\%) & $41(59)$ & $71(60)$ & 1.000 \\
\hline Previous AMI (\%) & $8(11)$ & $17(14)$ & 0.822 \\
\hline Previous CABG (\%) & $4(6)$ & $8(7)$ & 0.546 \\
\hline Previous Stroke/TIA (\%) & $6(9)$ & $4(3)$ & 0.144 \\
\hline
\end{tabular}

AMI $=$ acute myocardial infarction, $\mathrm{BMI}=$ body mass index, $\mathrm{CABG}=$ coronary artery bypass surgery, TIA $=$ transient ischemic attack. ${ }^{a}$ Waist circumference according to the National Cholesterol Education Program (NCEP).

There was a significant correlation between OGTT2h and PPG2h after breakfast $\left(\mathrm{r}^{2}=0.26, \mathrm{p}<0.001\right)$, lunch $\left(\mathrm{r}^{2}=0.13\right.$, $\mathrm{p}<0.001)$, and dinner $\left(\mathrm{r}^{2}=0.16, \mathrm{p}<0.001\right)$ (Fig. 3). Standardizing for age or body mass index did not change the results. The sensitivity of PPG2h for detecting AGT (according to OGTT limits) is $22 \%, 26 \%$, and $38 \%$ for breakfast, lunch detecting AGT is $100 \%, 83 \%$ and $83 \%$ for breakfast, lunch, and dinner respectively. The sensitivity of the single highest glucose value after any meal for detecting AGT was 52\% and the specificity was $71 \%$. Compared to morning and dinner respectively. The specificity of PPG $2 \mathrm{~h}$ for

OGTT2h, the sensitivity and specificity of PPG2h for detecting diabetes at the cut-off point of $5.6 \mathrm{mmol} / \mathrm{l}$ were $78.4 \%$ and $42.1 \%$ respectively. For lunch, the sensitivity and specificity of PPG2h at the cut-off point $6.5 \mathrm{mmol} / 1$ were $77.8 \%$ and $47.4 \%$ respectively, and for dinner, the sensitivity and specificity of PPG $2 \mathrm{~h}$ at $7.0 \mathrm{mmol} / 1$ were $76.5 \%$ and $55.1 \%$ respectively.

Table 2. Biochemistry of the patients with normal (NGT) or abnormal glucose tolerance (AGT) in hospital. Values are given as mean (SD or Q1,Q3).

\begin{tabular}{|l|c|c|c|}
\hline & NGT & AGT & P \\
\hline \hline Hemoglobin $(\mathrm{g} / \mathrm{l})$ & $132(17)$ & $132(18)$ & 0.899 \\
\hline Creatinine $(\mu \mathrm{mol} / \mathrm{l})$ & $77(18)$ & $82(20)$ & 0.111 \\
\hline eGFR $(\mathrm{CG}, \mathrm{ml} / \mathrm{min})$ & $96(31)$ & $96(35)$ & 0.887 \\
\hline Troponin T $(\mu \mathrm{g} / \mathrm{l})$ & $2.2(0.2,2.7)$ & $2.7(0.3,3.1)$ & 0.403 \\
\hline HbA $_{1 \mathrm{c}}(\%)$ & $5.4(0.5)$ & $5.5(0.5)$ & 0.623 \\
\hline Cholesterol $(\mathrm{mmol} / \mathrm{l})$ & $5.0(1.4)$ & $4.8(1.2)$ & 0.341 \\
\hline LDL-cholesterol $(\mathrm{mmol} / \mathrm{l})$ & $3.1(1.1)$ & $3.0(1.1)$ & 0.633 \\
\hline HDL-cholesterol $(\mathrm{mmol} / \mathrm{l})$ & $1.3(0.4)$ & $1.1(0.3)$ & 0.014 \\
\hline Triglycerides $(\mathrm{mmol} / \mathrm{l})$ & $1.5(0.8,1.6)$ & $1.9(1.0,2.1)$ & 0.012 \\
\hline
\end{tabular}

$\mathrm{CG}=$ Cockroft-Gault formula, eGFR $=$ estimated glomerular filtration rate, $\mathrm{HbA}_{\mathrm{lc}}=$ Glycated hemoglobin, HDL = high-density lipoprotein, $\mathrm{LDL}=$ low-density lipoprotein.

Table 3. Mean content of standard hospital diet.

\begin{tabular}{|c|c|c|c|}
\hline & Breakfast & Lunch & Dinner \\
\hline \hline Amount (g) & 564 & 674 & 607 \\
\hline Energy (kcal) & 383 & 545 & 483 \\
\hline $\begin{array}{c}\text { Carbohydrates } \\
(\mathrm{g})\end{array}$ & 48 & 58 & 62 \\
\hline Protein (g) & 23 & 30 & 23 \\
\hline Fat (g) & 11 & 20 & 15 \\
\hline SFA (g) & 5 & 6 & 6 \\
\hline
\end{tabular}

IGT
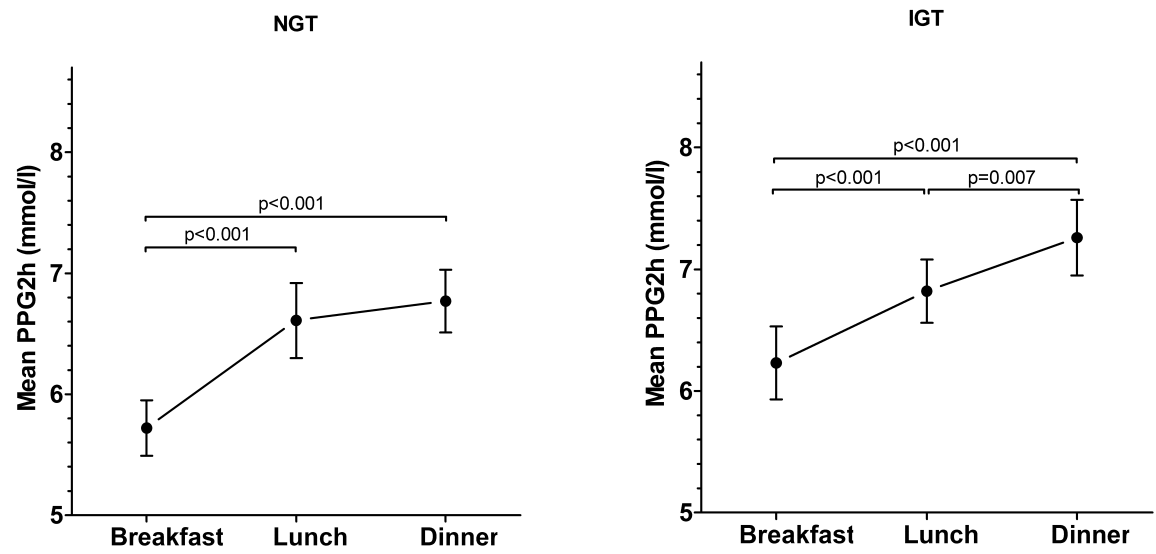

Fig. (2). Mean postprandial $( \pm 95 \% \mathrm{CI})$ glucose concentration (mmol/1) two hours after each daily meal (PPG2h) in three different patient groups according to an oral glucose tolerance test: normal glucose tolerance (NGT), impaired fasting glucose and glucose tolerance (IFG and IGT), and diabetes. 
BREAKFAST

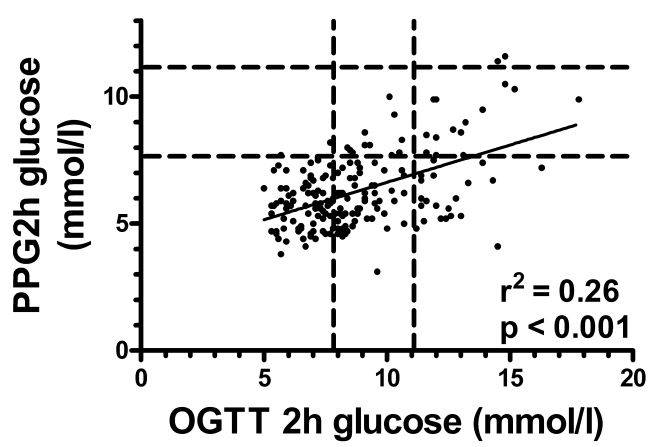

LUNCH

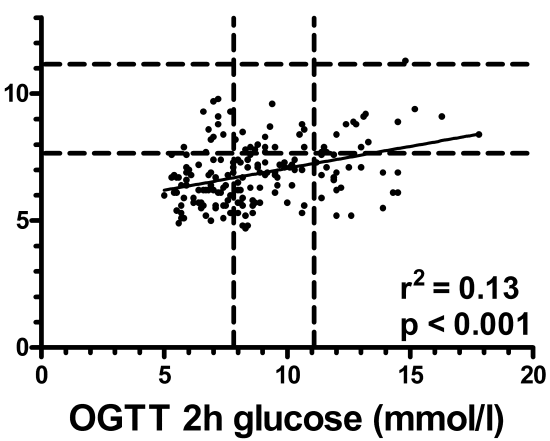

DINNER

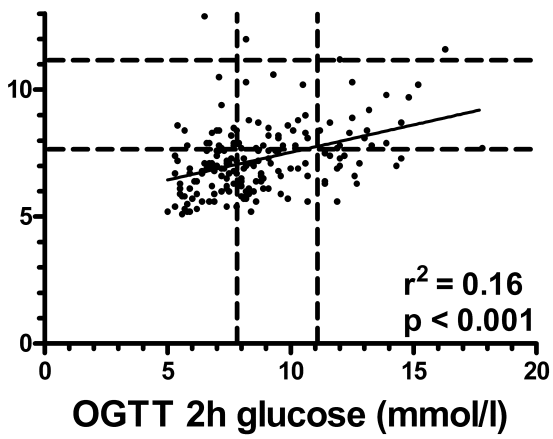

Fig. (3). Correlation between two-hour oral glucose tolerance test (OGTT2h) and two-hour postprandial glucose (PPG2h) at each daily meal in non-diabetic patients with acute myocardial infarction. Dashed lines represent glucose cut-off values of 7.8 and $11.1 \mathrm{mmol} / \mathrm{l}$.

\section{DISCUSSION}

This study is the first to demonstrate a correlation between PPG2h and OGTT2h in non-diabetic patients with acute myocardial infarction. PPG2h is very specific for categorizing glycemia but it lacks sensitivity with the glucose thresholds currently set for OGTT. New PPG2h threshold values are therefore suggested for the clinical decision to proceed to OGTT testing.

Plasma glucose is higher after OGTT compared to a standardized mixed meal [16]. Gastric emptying after liquid ingestion is more rapid than after a solid mixed meal, thus generating a non-physiologic inflow of glucose to the duodenum and portal vein circulation [22,23]. The protein and fat content of a meal may delay and attenuate the absorption of glucose and thereby produce a shallower pattern of PPG excursion [24,25]. In this study, the highest correlation between PPG2h and OGTT2h was seen after breakfast despite the lowest peak glucose (Fig. 2).

The correlation between PPG and OGTT $\left(r^{2}=0.13-0.26\right.$, $p<0.001$; Fig. 3) in the present study supports the findings of earlier studies. This is the case even though our patients were acutely ill and we measured PPG2h after non-standardized everyday hospital meals. Meier et al. [16] demonstrated a correlation between a standardized mixed meal and OGTT $\left(\mathrm{r}^{2}=0.78\right)$ and self-measured home profiles and OGTT $\left(\mathrm{r}^{2}=\right.$ $0.34)$. Oka et al. [26] reported a loose correlation $\left(\mathrm{r}^{2}=0.11\right)$ between a standardized rice-based meal and OGTT2h in a population sample. The strict testing protocol by Meier et al. [16] gives a high correlation between OGTT2h and PPG2h, but with a more practical approach at home or on the ward, as in the present study, the correlation is less substantial. More uncertainty must be accepted if patients are tested by the more practical method compared to a strict laboratory methodology when assessing postprandial glycemia.

In the study by Meier et al. [16], non-diabetic patients categorized by OGTT also had normoglycemia two hours after breakfast, lunch and dinner. In our NGT group, despite normal PPG2h after breakfast, the PPG2h after lunch and dinner was increased. Similarly, PPG2h was higher after lunch and dinner compared to breakfast in the IGT group. This raises the question of whether patients in the NGT group have a transient stress-induced disturbance in glycemic tolerance due to acute myocardial infarction. A similar pattern of stress-induced post-meal glycemic changes has been reported after prosthetic surgery [27]. Acute stressinduced hyperglycemia is also supported by a study where $61 \%$ of non-diabetic patients with acute stroke had AGT at discharge, but after re-investigation at three months more than half of them were categorized as having NGT [28]. By contrast, in the study by Wallander et al. [29], 93\% of newly detected diabetic patients evaluated by OGTT during acute myocardial infarction at discharge still had AGT after 3 and 12 months. This is supported by our finding that OGTT2h did not change within the one-month spectrum of sampling. Thus, there is contradictory evidence about the transitory nature of hyperglycemia related to acute severe illness.

The epidemiological data support the hypothesis that postprandial hyperglycemia, not FPG, is the risk factor for cardiovascular diseases [14]. In the Diabetes Intervention Study (DIS), the blood glucose after breakfast, not fasting blood glucose, predicted myocardial infarction and mortality in newly diagnosed type 2 diabetic patients [13]. Postprandial blood glucose has been found to be a stronger predictor of cardiovascular events than fasting blood glucose in all type 2 diabetic patients, especially in women [11].

AGT defined by OGTT is suggested to be a good risk marker for determining cardiovascular prognosis after myocardial infarction [8]. In our study, there was a firm correlation between OGTT2h and PPG2h. Measuring PPG2h instead of OGTT2h could be an easier and more practical way to evaluate the postprandial glycemic state after myocardial infarction in clinical practice. All measurements in our study were made during routine care on the ward. The only exception to normal care was the PPG measurement three times a day. There are no studies on the role of PPG as a surrogate after acute myocardial infarction in the nondiabetic population. A study comparing the PPG2h to OGTT2 $\mathrm{h}$ as a cardiovascular risk marker is therefore called for.

The pathogenesis of type 2 diabetes mellitus supports the screening of postprandial hyperglycemia instead of fasting glucose or $\mathrm{HbA}_{1 \mathrm{c}}$ in the non-diabetic population [2]. Only after the postprandial glycemic control is lost will the deterioration of fasting hyperglycemia ensue [3]. Initial decrease of postprandial insulin release and also insulin resistance have been proposed to be genetically transmitted risk factors predisposing individuals to type 2 diabetes [4]. In patients with IGT, decreasing PPG with acarbose was 
associated with a lower incidence of cardiovascular events in the STOP-NIDDM Study [12].

Norhammar et al. showed that OGTT can predict cardiovascular events in patients with myocardial infarction. We adopted a similar study design to compare PPG2h to OGTT2h. Despite similar inclusion criteria and the very similar population and way of living in Sweden and Finland, these two studies have some differences. First, fasting glucose criteria for diagnosing diabetes differ between the World Health Organization and American Diabetic Association. Second, whole blood glucose levels are 12\% lower than plasma glucose. Plasma sampling in our study should increase detection of IGT and diabetes. Third, compared to the patients of Norhammar et al. [30] our patients were older, more obese, and had more a frequent history of hypertension, which would be expected to increase the number of AGT patients. Instead, compared to the study population of Norhammar et al. [30], there were fewer new diabetic patients $(21 \%$ vs. $33 \%)$ but hardly any difference in the number of AGT patients $(63 \%$ vs. $68 \%)$. The best explanation for these differences is the program for the prevention of type 2 diabetes in Finland, which was conducted during 2003-2008 [31].

There are a number of limitations in our study. First, during our study a great majority of patients left hospital before being able to participate in the study. They were either not given permission to eat regular meals before transfer to another unit or they did not have time for OGTT. We cannot exclude the possibility that the study population is biased to include more sick and older people and complicated cases. Second, we did not record what proportion of food was eaten, which may increase the number of false negative results. Third, we did not standardize meal size or the content of carbohydrates, protein or fat. Fourth, medication was recorded only at discharge. However, the effect of medications on the OGTT and PPG2h measurements are similar.

On the other hand, the strength of this study, is a practical everyday approach in evaluating postprandial glycemia.

\section{CONCLUSION}

PPG2h is a quick, practical, simple and easy estimate for evaluating postprandial glycemia after myocardial infarction in clinical practice. Because the PPG2h value is lower than OGTT2h, the sensitivity of PPG $2 h$ in detecting IGT and diabetes is low with the current cut-off values designed for OGTT. New cut-off values for PPG2h are therefore suggested. The new values could be used to find patients in whom further testing by OGTT is not needed.
ABBREVIATIONS
AGT $=$ Abnormal glucose tolerance
FPG $=$ Fasting plasma glucose
GFR $=$ Glomerular filtration rate
$\mathrm{HbA}_{1 \mathrm{c}}=$ Hemoglobin $\mathrm{A}_{1 \mathrm{c}}$
IGT $=$ Impaired glucose tolerance
NGT $=$ Normal glucose tolerance
OGTT $=$ Oral glucose tolerance test

OGTT2h $=$ Two-hour oral glucose tolerance test

PPG = Postprandial glucose

PPG2h $=$ Two-hour postprandial glucose

ROC $=$ Receiver operating characteristic

SD $\quad=$ Standard deviation

\section{CONFLICT OF INTEREST}

No competing financial interest exists for any author.

\section{ACKNOWLEDGEMENTS}

The expert assistance of Mrs. Kati Peltomäki, RN, is gratefully acknowledged. This study was supported by The Heart Center, Tampere University Hospital, Tampere, Finland and the Department of Internal Medicine, Tampere University Hospital, Tampere, Finland. Funding sources had no involvement in the study.

\section{REFERENCES}

[1] Coutinho M, Gerstein HC, Wang Y, Yusuf S. The relationship between glucose and incident cardiovascular events. A metaregression analysis of published data from 20 studies of 95,783 individuals followed for 12.4 years. Diabetes Care 1999; 22: $233-40$.

[2] Woerle HJ, Pimenta WP, Meyer C, et al. Diagnostic and therapeutic implications of relationships between fasting, 2-hour postchallenge plasma glucose and hemoglobin a1c values. Arch Intern Med 2004; 164: 1627-32.

[3] Monnier L, Colette C, Dunseath GJ, Owens DR. The loss of postprandial glycemic control precedes stepwise deterioration of fasting with worsening diabetes. Diabetes Care 2007; 30: 263-9.

[4] Gerich JE. Is reduced first-phase insulin release the earliest detectable abnormality in individuals destined to develop type 2 diabetes? Diabetes 2002; 51 (Suppl 1): 117-21.

[5] Van Haeften TW. Early disturbances in insulin secretion in the development of type 2 diabetes mellitus. Mol Cell Endocrinol 2002; 197: 197-204

[6] Henquin J-C, Ishiyama N, Nenquin M, Ravier MA, Jonas J-C. Signals and pools underlying biphasic insulin secretion. Diabetes 2002; 51 (Suppl 1): 60-7.

[7] DECODE Study Group, the European Diabetes Epidemiology Group. Glucose tolerance and cardiovascular mortality: comparison of fasting and 2-hour diagnostic criteria. Arch Intern Med 2001; 161: 397-405.

[8] Bartnik M, Malmberg K, Norhammar A, Tenerz A, Ohrvik J, Rydén L. Newly detected abnormal glucose tolerance: an important predictor of long-term outcome after myocardial infarction. Eur Heart J 2004; 25: 1990-7.

[9] Capes SE, Hunt D, Malmberg K, Gerstein HC. Stress hyperglycemia and increased risk of death after myocardial infarction in patients with and without diabetes: a systematic overview. Lancet 2000; 355: 773-8.

[10] Tamita K, Katayama M, Takagi $\mathrm{T}$, et al. Impact of newly diagnosed abnormal glucose tolerance on long-term prognosis in patients with acute myocardial infarction. Circ J 2007; 71: 834-41.

[11] Cavalot F, Petrelli A, Traversa M, et al. Postprandial blood glucose is a stronger predictor of cardiovascular events than fasting blood glucose in type 2 diabetes mellitus, particularly in women: lessons from the San Luigi Gonzaga Diabetes Study. J Clin Endocrinol Metab 2006; 91: 813-9.

[12] Chiasson J-L, Josse RG, Gomis R, et al. Acarbose treatment and the risk of cardiovascular disease and hypertension in patients with impaired glucose tolerance: the STOP-NIDDM trial. JAMA 2003; 290: 486-94.

[13] Hanefeld M, Fischer S, Julius U, et al. Risk factors for myocardial infarction and death in newly detected NIDDM: the Diabetes Intervention Study, 11-year follow-up. Diabetologia 1996; 39: 1577-83.

[14] Ceriello A, Hanefeld M, Leiter L, et al. Postprandial glucose regulation and diabetic complications. Arch Intern Med 2004; 164: 2090-5. 
[15] Authors/Task Force Members, Rydén L, Grant PJ, et al. ESC Guidelines on diabetes, pre-diabetes, and cardiovascular diseases developed in collaboration with the EASD: the Task Force on diabetes, pre-diabetes, and cardiovascular diseases of the European Society of Cardiology (ESC) and developed in collaboration with the European Association for the Study of Diabetes (EASD). Eur Heart J 2013; 34: 3035-87.

[16] Meier JJ, Baller B, Menge BA, Gallwitz B, Schmidt WE, Nauck MA. Excess glycaemic excursions after an oral glucose tolerance test compared with a mixed meal challenge and self-measured home glucose profiles: is the OGTT a valid predictor of postprandial hyperglycemia and vice versa? Diabetes Obes Metab 2009; $11: 213-22$

[17] Raz I, Wilson PWF, Strojek K, et al. Effects of prandial versus fasting glycemia on cardiovascular outcomes in type 2 diabetes: the HEART2D trial. Diabetes Care 2009; 32: 381-6.

[18] Myocardial infarction redefined - a consensus document of The Joint European Society of Cardiology/American College of Cardiology Committee for the redefinition of myocardial infarction. Eur Heart J 2000; 21: 1502-13.

[19] Thygesen K, Alpert JS, White HD, Joint ESC/ACCF/AHA/WHF Task Force for the Redefinition of Myocardial Infarction. Universal definition of myocardial infarction. Eur Heart J 2007; 28: 2525-38.

[20] Cockcroft DW, Gault MH. Prediction of creatinine clearance from serum creatinine. Nephron 1976; 16: 31-41.

[21] Levey AS, Bosch JP, Lewis JB, Greene T, Rogers N, Roth D. A more accurate method to estimate glomerular filtration rate from serum creatinine: a new prediction equation. Modification of Diet in Renal Disease Study Group. Ann Intern Med 1999; 130: 461-70.

[22] Alberti KG, Zimmet PZ. Definition, diagnosis and classification of diabetes mellitus and its complications. Part 1: diagnosis and classification of diabetes mellitus provisional report of a WHO consultation. Diabet Med 1998; 15: 539-53.
[23] Collins PJ, Horowitz M, Cook DJ, Harding PE, Shearman DJ. Gastric emptying in normal subjects--a reproducible technique using a single scintillation camera and computer system. Gut 1983; 24: $1117-25$

[24] Carrel G, Egli L, Tran C, et al. Contributions of fat and protein to the incretin effect of a mixed meal. Am J Clin Nutr 2011; 94: 9971003 .

[25] Manders RJF, Wagenmakers AJM, Koopman R, et al. Co-ingestion of a protein hydrolysate and amino acid mixture with carbohydrate improves plasma glucose disposal in patients with type 2 diabetes. Am J Clin Nutr 2005; 82: 76-83.

[26] Oka R, Hifumi S, Kobayashi J, et al. The relationship between post-prandial plasma glucose and post-challenge plasma glucose in Japanese population. Diabetes Res Clin Pract 2007; 78: 282-8.

[27] Pili-Floury S, Mitifiot F, Penfornis A, et al. Glycaemic dysregulation in nondiabetic patients after major lower limb prosthetic surgery. Diabetes Metab 2009; 35: 43-8.

[28] Dave JA, Engel ME, Freercks R, et al. Abnormal glucose metabolism in non-diabetic patients presenting with an acute stroke: prospective study and systematic review. QJM 2010; 103 : 495-503.

[29] Wallander M, Malmberg K, Norhammar A, Rydén L, Tenerz A. Oral glucose tolerance test: a reliable tool for early detection of glucose abnormalities in patients with acute myocardial infarction in clinical practice: a report on repeated oral glucose tolerance tests from the GAMI study. Diabetes Care 2008; 31: 36-8.

[30] Norhammar A, Tenerz A, Nilsson G, et al. Glucose metabolism in patients with acute myocardial infarction and no previous diagnosis of diabetes mellitus: a prospective study. Lancet 2002; 359: 21404.

[31] Saaristo T, Peltonen M, Keinänen-Kiukaanniemi S, et al. National type 2 diabetes prevention programme in Finland: FIN-D2D. Int J Circumpolar Health 2007; 66: 101-12.

(C) Arola et al.; Licensee Bentham Open.

This is an open access article licensed under the terms of the Creative Commons Attribution Non-Commercial License (http://creativecommons.org/licenses/ by-nc/3.0/) which permits unrestricted, non-commercial use, distribution and reproduction in any medium, provided the work is properly cited. 